\title{
A determination of emergency department pre-triage times in patients not arriving by ambulance compared to widely used guideline recommendations
}

\author{
Martin Betz, MD*+ James Stempien, BSc, MD*; Sachin Trivedi, BSc, MD; Rhonda Bryce, MSc, MD ${ }^{\S}$
}

\section{ABSTRACT}

Objectives: Emergency department (ED) lengths of stay are measured from the time of patient registration or triage. The time that patients wait in line prior to registration and triage has not been well described. We sought to characterize pre-triage wait times and compare them to recommended physician response times, as per the Canadian Triage and Acuity Scale (CTAS).

Methods: This observational study documented the time that consenting patients entered the ED and the time that they were formally registered and triaged. Participants' CTAS scores were collected from the electronic record. Patients arriving to the ED by ambulance were excluded.

Results: A total of 536 participants were timed over 13 separate intervals. Of these, 11 left without being triaged. Participants who scored either CTAS 1 or $2(n=53)$ waited a median time of 3.1 (interquartile range [IOR]: 0.43, 11.1) minutes. Patients triaged as CTAS $3(n=187)$ waited a median of 11.4 (IQR: 1.6, 24.9) minutes, CTAS $4(n=139)$ a median of 16.6 (IQR: $6.0,29.7)$ minutes, and CTAS $5(n=146)$ a median of 17.5 (IQR: $6.8,37.3$ ) minutes. Of patients subsequently categorized as CTAS 1 or 2 , $20.8 \%$ waited longer than the recommended time-to-physician of 15 minutes to be triaged.

Conclusions: All urban EDs closely follow patients' wait times, often stratified according to triage category, which are assumed to be time-stamped upon a patient's arrival in the ED. We note that pre-triage times exceed the CTAS recommended time-tophysician in a possibly significant proportion of patients. EDs should consider documenting times to treatment from the moment of patient arrival rather than registration.

\section{RÉSUMÉ}

Introduction: La durée du séjour (DS) au service des urgences (SU) se mesure depuis le moment de l'inscription ou celui du triage. Toutefois, le délai d'attente écoulé avant l'inscription ou le triage est mal connu. Aussi les auteurs ont-ils cherché à caractériser le délai d'attente avant le triage et à le comparer avec le délai pour l'évaluation initiale par le médecin, recommandé dans l'Échelle canadienne de triage et de gravité (ECTG).

Méthode: II s'agit d'une étude d'observation dans laquelle ont été recueillies des données sur le délai d'attente des patients qui sont arrivés au SU et qui ont accepté de participer à l'étude, et sur le délai d'attente avant qu'ils soient officiellement inscrits et triés. Les cotes de priorité relatives à I'ECTG ont été recueillies à l'aide des dossiers électroniques. Les patients qui sont arrivés au SU en ambulance ont été exclus. Résultats: A été mesuré le délai d'attente de 536 participants sur 13 périodes distinctes. Sur ce nombre, 11 malades sont partis sans avoir été triés. Le délai d'attente médian chez les participants qui avaient reçu une cote 1 ou 2 selon I'ECTG $(n=53$ ) était de 3,1 minutes (écart interquartile [EI] : 0,43 $11,1)$. Quant au délai d'attente médian chez les participants qui avaient reçu une cote $3(n=187)$, il était de 11,4 minutes (El : 1,6 - 24,9); chez ceux qui avaient reçu une cote 4 ( $n=139$ ), il était de 16,6 minutes ( $E I: 6,0-29,7$ ) et chez ceux qui avaient reçu une cote 5 ( $n=146$ ), il était de 17,5 minutes (El : 6,8 - 37,3). Enfin, 20,8\% des patients ayant reçu ultérieurement une cote 1 ou 2 selon I'ECTG ont attendu plus longtemps que le délai recommandé de 15 minutes pour l'évaluation initiale par un médecin avant d'être triés.

Conclusions: Les délais d'attente, qui sont souvent répartis selon la cote de priorité et que l'on suppose horodatés à l'arrivée des patients, font l'objet d'un suivi étroit dans tous les $\mathrm{SU}$ urbains. Les auteurs ont toutefois relevé que les délais d'attente avant le triage dépassaient le délai recommandé pour l'évaluation initiale par un médecin selon l'ECTG, et ce, dans une proportion vraisemblablement importante de patients. Aussi les SU devraient-ils calculer le temps écoulé avant le traitement depuis l'arrivée des patients plutôt que depuis leur inscription.

Keywords: Emergency medicine, triage, CTAS, patient wait times

From the *Department of Emergency Medicine, Saskatoon Health Region, St. Paul's Hospital, Saskatoon, SK; †Department of Emergency Medicine, Sunnybrook Health Sciences Centre, Toronto, ON; and the $¥$ College of Medicine and §Clinical Research Support Unit, University of Saskatchewan, Saskatoon, SK.

Correspondence to: Dr. Martin Betz, Department of Emergency Medicine, Sunnybrook Health Sciences Centre, 2075 Bayview Avenue, Room C753, Toronto, ON M4N 3M5; Email: mgbetz@ hotmail.com

Note: A previous error in this article has been corrected. Please see 10.1017/cem.2017.18 for details. 


\section{INTRODUCTION}

Triage algorithms are tools that were developed to enable emergency departments (EDs) to prioritize patient care requirements based on the type and severity of their presenting complaints and vital signs abnormalities. Their intent is to ensure that the sickest patients are seen first when the rate of patient arrival exceeds the capacity of medical personnel to safely and appropriately assess and manage all patients.

Although virtually all EDs in North America use formal triage processes, doubts have been expressed about their clinical utility. ${ }^{1}$ Under some circumstances, formal triage has been thought to contribute to excessive wait times. ${ }^{2}$ Although the definition of wait times in most studies almost universally refers to the time a patient waits for first contact with a physician, the time at which the clock starts ticking is variable and can be vague, defined as "when patients arrived in the $\mathrm{ED}^{3}$ or, more often, the time of registration (TR) or triage as documented on the medical record by an intake clerk or nurse. ${ }^{4}$ Internationally recognized triage systems have all recommended maximum wait times based on a patient's assigned triage category. For example, The Manchester Triage System specifies no more than 10 minutes for Category 2 patients and immediate assessment for those triaged as Category $1 .^{5}$ The Emergency Severity Index (ESI) had recommended that Category 1 (most acutely ill) patients be seen immediately and that Category 2 patients be seen in 14 minutes or less, although time-to-physician guidelines no longer appear in the latest version. ${ }^{6}$ The Canadian Triage and Acuity Scale (CTAS) originally specified times to be seen for each category: CTAS 1 is immediately, CTAS 2 is 15 minutes, CTAS 3 is 30 minutes, CTAS 4 is 60 minutes, and CTAS 5 is 120 minutes. Later revisions have de-emphasized timeto-physician and urged focus on time to disposition and nurse reassessment. ${ }^{7}$ In all cases, wait times are based on an identified time of arrival (TA) of patients at the ED.

When examining reports generated by our hospitals' quality assurance departments, we have noted that wait times are calculated using TR. This assumes that there is little difference between the registration time and the actual TA in the ED.

There are few published guidelines regarding what are acceptable wait-times to see a physician, ${ }^{8}$ let alone to be triaged. Prolonged ED length of stay may be associated with adverse outcomes for patients experiencing them. ${ }^{9}$
It seems self-evident that extremely long time-to-triage times could result in adverse outcomes.

There is a dearth of published studies looking at whether there are significant discrepancies between these two times in hospital EDs. In our own EDs, we have increasingly noted queues of people in front of the triage desk. This study is an attempt to quantify the difference in TA from the TR, in order to consider whether it is significant in enough patients to possibly jeopardize the validity of quality assessments and, more important, patient care.

\section{METHODS}

This study, designed as a prospective observational study, was conducted in the EDs of two urban hospitals. These are tertiary care, university-affiliated teaching hospitals, located in a city of 250,000 , with a combined annual census of more than 90,000 patients per year. The University of Saskatchewan Biomedical Research Ethics Board categorized the proposal as a quality improvement/program evaluation study and, as per issued statement Bio-REB \#13-102, granted permission to conduct the study.

The subjects for this study were persons presenting to the ED with the intent of seeking medical care for an injury or illness. Exclusion criteria included refusal or the inability to give consent to take part in the study, and arrival by ambulance. Enrolment was consecutive during 13 blocks of time, set at various times of the day between 0730 and 1600 hours. They were chosen at convenience over a period of 2 weeks, but with the aim to sample triage events at nearly all times of the day.

All potential subjects were approached by a single observer (ST) who stationed himself at the entrance to the department. If they identified themselves as wanting to see a physician, informed oral consent to participate was sought. Potential subjects were advised that they were being asked for information as part of a study on ED waiting times. The data obtained from each subject included the patient's age, sex, and initials. The date and exact TA were recorded. Subsequently, the TA as recorded on the chart, equivalent to the TR, and CTAS score, were obtained from the electronic medical record for each patient. In the study EDs, time of triage and TR are interchangeable. Although most patients are triaged before actually being registered by an intake clerk, the TR recorded on the medical record is whichever time is earliest. 
The data were collected from subjects, recorded by hand, and subsequently transcribed onto an Excel spreadsheet (Microsoft, Redmond, WA, USA). Data from the patient's electronic record were added to this spreadsheet. Basic descriptive statistical analysis was performed using SAS software, version 9.3 (SAS Institute Inc., Cary, NC, USA).

The primary outcome was the calculated difference between the TA and TR, identified as the pre-triage time (PTT). Pre-determined statistical analyses included calculation of the mean, median, interquartile range (IQR), and range of differences for all subjects and for subgroups based on age, time of day, and CTAS score.

In designing the study, a sample size determination was made based on the detection of what was felt might be an important prolonged PTT for a significant proportion of CTAS 1-2 patients. Any PTT approaching the CTAS recommended time to see a physician of 15 minutes was thought to be significant in this subgroup. Finding a prolonged PTT of this degree, in more than a quarter of this population, was viewed as clinically significant. A sample population of 50 CTAS 1-2 patients was felt to provide some confidence in allowing us to evaluate our hypothesis that a significant number of patients $(\geq 12)$ had excessive PTTs. Based on the EDs' usual proportion of patients triaged to CTAS $1-2$ of $10 \%$, the aim was to enrol a total of 500 subjects.

All of the emergency physicians working at the two study hospitals were invited to answer a simple online questionnaire concerning their attitudes to triage times. What is the maximum time that patients should wait to be triaged, in the context of an acceptable level of risk to patients balanced with reasonable resource utilization? The survey results were analysed with simple descriptive statistics.

\section{RESULTS}

\section{Survey of emergency physician opinion for reasonable time-to-triage}

Nineteen emergency physicians, approximately one third of those eligible, provided answers to questions regarding triage timing. Sixteen of the nineteen (84\%) emergency physicians believed that patients arriving at the ED should be triaged within 5 minutes or less (Figure 1), to achieve a reasonable balance between risk of harm from delay in delivery of medical care and

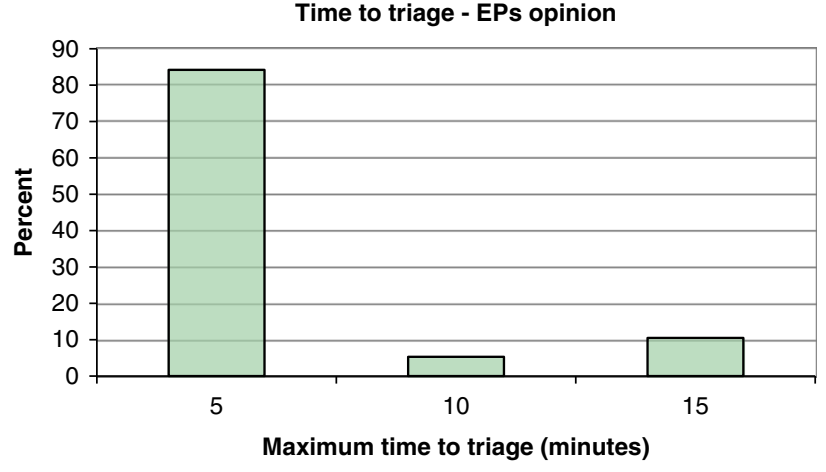

Figure 1. Emergency physicians' opinions $(n=19)$ of the maximum time patients should wait to be triaged after arriving in the ED, in minutes. This time is based on the possibility that a patient might be categorized at CTAS level 2.

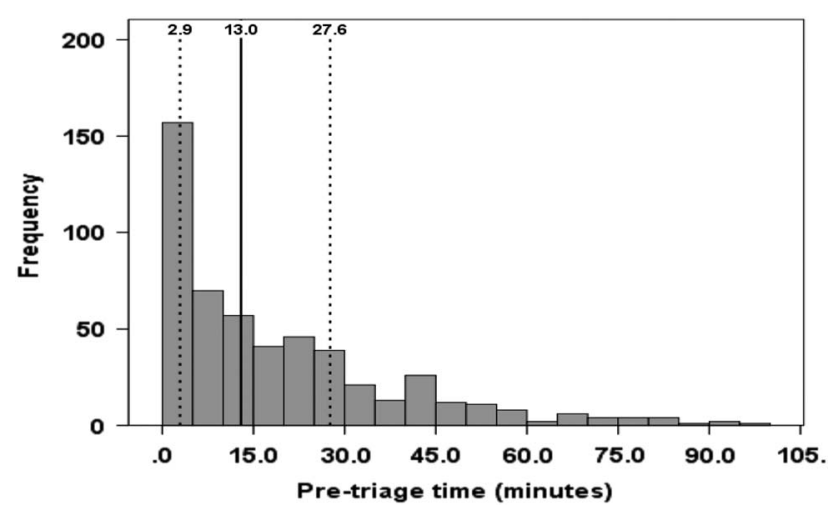

Figure 2. Distribution of pre-triage times in all subjects. Solid vertical line represents the median time; broken lines represent 25th and 75th percentiles.

resource utilization. Most (58\%) felt that $80 \%$ to $90 \%$ of arriving patients should meet this 5 -minute triage standard.

\section{Time waiting to be triaged}

A total of 541 people were approached upon their arrival in the ED. Eight declined to be included in the study. Eight more agreed to be enrolled but finally were directed to areas of the hospital other than the ED for care. Of 525 people who were enrolled in the study, 11 $(2 \%)$ decided not to wait to be triaged and registered as patients in the ED. As illustrated in Figure 2, the median time between arrival and registration (PTT) for all subjects was 13 minutes with a range of 0.5 to 98.6 minutes. Median PTTs, with range and IQR, by age group, time of day, and subsequent CTAS score, are shown in Table 1. 


\begin{tabular}{|c|c|c|c|}
\hline Characteristic & $N$ & $\begin{array}{l}\text { Median time } \\
(\mathrm{IQR})-\mathrm{min}\end{array}$ & Range \\
\hline All subjects & 525 & $13.0(2.9,27.6)$ & $0.05,98.6$ \\
\hline Non-triaged subjects & 11 & & \\
\hline \multicolumn{4}{|l|}{ By age group - years } \\
\hline Infant $(<1)$ & 34 & $5.7(0.4,16.0)$ & $0.05,72.2$ \\
\hline Child (1-6) & 39 & $8.2(1.6,16.2)$ & $0.05,43.8$ \\
\hline Pre-teen (7-12) & 25 & $10.8(6.5,19.8)$ & $0.5,73.3$ \\
\hline Teen (13-19) & 26 & $12.5(3.6,24.2)$ & $0.12,63.3$ \\
\hline Adult (20-65) & 307 & $15.8(3.0,29.9)$ & $0.05,98.6$ \\
\hline Geriatric (>65) & 94 & $15.1(5.3,30.5)$ & $0.05,76.3$ \\
\hline \multicolumn{4}{|l|}{ By time of day - hh.mm } \\
\hline Morning (07.30-11.59) & 147 & $14.6(4.2,23.8)$ & $0.05,79.8$ \\
\hline Afternoon (12.00-17.59) & 273 & $17.6(6.1,36.4)$ & $0.05,98.6$ \\
\hline Evening (18.00-23.59) & 91 & $4.5(0.4,14.0)$ & $0.05,50.2$ \\
\hline Night (00.00-07.59) & 14 & $2.8(0.2,17.4)$ & $0.08,35.6$ \\
\hline \multicolumn{4}{|l|}{ By CTAS $^{*}$} \\
\hline 1 or 2 & 53 & $3.1(0.4,11.1)$ & $0.05,44.2$ \\
\hline 3 & 187 & $11.4(1.6,24.9)$ & $0.05,91.1$ \\
\hline 4 & 139 & $16.6(6.0,29.7)$ & $0.06,98.6$ \\
\hline 5 & 146 & $17.5(6.8,37.3)$ & $0.05,90.4$ \\
\hline
\end{tabular}

The distribution of PTTs (median, mean, IQR, and outliers) by CTAS category is shown in Figure 3 together with the recommended time-to-physician for each category. Ten percent of all patients exceeded recommended CTAS wait times based solely on PTT. The proportion of patients waiting longer than recommended increased as the triage category became more acute (Table 2; see Figure 3).

\section{DISCUSSION}

EDs in North American urban areas have faced steadily increasing patient visits for many years. ${ }^{3,10}$ Triage of patients on arrival, using formal triage systems, has been the default method of attempting to limit adverse outcomes among patients having to wait for assessment by a medical professional.

Hospitals have collected triage statistics for various reasons, some of them mandated by government agencies, but wait times are universally included. Time-to-physician is a quality indicator in many institutions, especially when applied to the more acute triage categories. The four most widely used triage systems have at some point all listed similar recommended maximum time-to-physician limits, although many have retreated from these

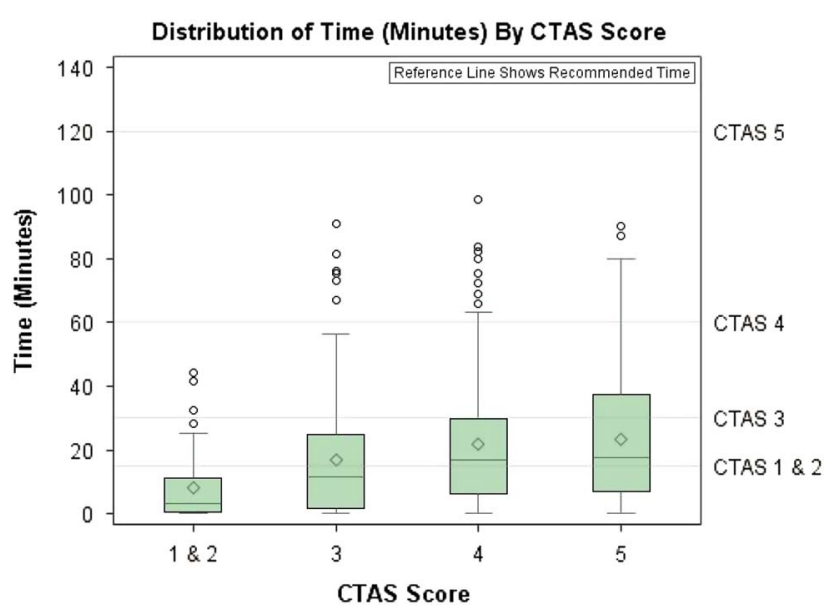

Figure 3. Boxes represent the interquartile range (IQR) of the given times-to-triage; the solid line in the box represents the median time, diamonds represent the mean time; T-bars represent relatively extreme values $(150 \%$ of the QRs outside of 25 to 75 percentiles); circles represent individual outlier values.

Table 2. Pre-triage time compared to time-to-physician guidelines (CTAS)

\begin{tabular}{lccr}
$\begin{array}{l}\text { CTAS } \\
\text { category }\end{array}$ & $\begin{array}{c}\text { Meets guidelines } \\
(\%)\end{array}$ & $\begin{array}{c}\text { Greater than } \\
\text { guidelines }(\%)\end{array}$ & Total (\%) \\
\hline 1 or ${ }^{*}$ & $42(79.2)$ & $11(20.8)$ & $53(100)$ \\
3 & $153(81.8)$ & $10(7.2)$ & $139(100)$ \\
4 & $129(92.8)$ & $10(7.2)$ & $139(100)$ \\
5 & $146(100)$ & 0 & $146(100)$ \\
Total & $470(89.5)$ & $55(10.5)$ & $525(100)$ \\
\hline *Includes one CTAS 1 patient who was seen immediately upon arrival. & \\
\hline
\end{tabular}

recommendations recently, perhaps because there is little outcome-based research to back them. However, recommended time-to-physician standards seem to have been implicitly accepted by many physicians as reasonable, if increasingly difficult to meet.

An assumption has been that these times-to-physician begin immediately upon patients' arrival in the ED. We know of only one study assessing the accuracy of the time captured on the medical record of patients arriving in an ED. ${ }^{11}$ The authors found that the median time to triage was 10 minutes (IQR 5-19, range 0-105), similar to our results. In their single hospital study, they report that $55 \%$ of patients requiring triage waited longer than 10 minutes. However, these proportions are calculated strictly on the $15.4 \%$ of patients who had to wait to be triaged and excluded patients arriving by ambulance, those taken immediately to a treatment area and those who were triaged immediately. 
The longer PTTs we noted in patients subsequently assigned less acute triage categories likely is a reflection of the influence of non-formal triage processes. The EDs in this study both allow the triage nurse to see directly all patients as they arrive through the entrance door and in any queue. Undoubtedly, patients who appeared frankly ill were brought to the front of a queue. An additional factor may be patients who triage themselves, either requesting to be seen first, or being "pushed" to the head of the queue by other patients waiting. These informal triage processes are largely unstudied, their importance under-recognized by managers, and probably play an important role in increasing patient safety in volume-stressed EDs.

What is an acceptable time to triage for patients arriving other than by the emergency medical services (EMS) at the ED? A survey of ED physicians in this study revealed that a majority (60\%) felt that at least $90 \%$ patients should be assessed by a triage nurse within 10 minutes of arriving. We could find no published information from other centres for comparison. One might assume it should be no more than the shortest time-to-physician specified by the triage system's highest acuity categories.

A number of medical conditions are the subject of specialist society-sponsored guidelines for therapy to be started within specified time limits. These include acute ST-elevation myocardial infarction (STEMI) ${ }^{12}$ and acute ischemic stroke. ${ }^{13}$ It is increasingly recognized that improved patient outcomes result from earlier management of many other conditions, including septic shock, ${ }^{14}$ pneumonia, ${ }^{15}$ and shock due to trauma and burns. Many published studies evaluating these guidelines use timeto-treatment, if defined at all, with the TA set as the TR. Data collected in our study suggest that the PTTs are long enough in a significant proportion of patients, particularly those triaged as CTAS Categories 1 and 2, to make meeting triage system time-to-physician guidelines difficult or impossible. These PTTs could be clinically significant in patients eventually identified as candidates for guideline-based, time-sensitive therapies.

\section{LIMITATIONS}

There are inherent weaknesses to an observational study such as the one undertaken. As subjects were observed within a limited number of time intervals, which did not cover all times of the day and days of the week equally, results may be more representative of triage that occurs during daytime and early evening hours. Weekdays were overrepresented compared to weekends.

Although the intention of this study was to include the measurement of PTTs for the patient subgroups listed, judging the clinical importance of differences among subgroups is problematic when not definitively planned for. Differences in PTTs among subgroups based on patient characteristics, as presented in Table 1 (e.g., longer times for adults versus children, day versus night), should be seen as potential, given they are unadjusted for possible confounding relationships between factors.

We believe that this study fairly accurately assesses aspects of the triage processes used in many other North American EDs. It is likely that a significant proportion of patients arriving at most EDs experience excessive times simply waiting to be triaged. This may represent an under-recognized health care system problem, which should at least be broadly assessed. EDs should consider instituting methods to document actual patient arrival times. This might be accomplished by something as simple as asking arriving patients to take a number, which could be time-stamped electronically. Other solutions might include various methods of self-triage or self-check-in, perhaps with computer assistance.

The two EDs involved in this study instituted changes to address the potential risk of prolonged PTTs. Sight lines by TNs were further improved through rearrangement of intake desks. A new nursing position was created at one hospital with the function of assessing patients at busy periods, as they arrive and while waiting. Whether adding an additional layer to an already complex triage process reduces risk of adverse patient outcomes needs study, considering the extra resources required.

\section{CONCLUSION}

Triage of patients on arrival to hospital EDs is performed in an attempt to limit adverse outcomes among patients facing prolonged wait times for assessment by a medical professional, especially if suffering from a condition where time-critical interventions exist. Timeto-physician data are also an important quality of care statistic used by health care institutions to monitor performance.

In this study of 525 patients arriving at two EDs, more than $10 \%$ of all patients have a time-to-triage that exceeds recommended CTAS time-to-physician 
assessment times. Among patients subsequently triaged to Category 2, the proportion is more than $20 \%$.

It seems prudent to conclude that EDs, associated health authorities, and national organizations should at least assess the problem of pre-triage wait times and consider instituting methods to document actual patient arrival times. The time waiting to be triaged may, in many EDs, represent an unrecognized opportunity to improve patient outcomes if strategies can be developed to decrease this delay.

Competing interests: None declared.

\section{REFERENCES}

1. Weber EJ, McAlpine BA, Grimes B. Mandatory triage does not identify high-acuity patients within recommended time frames. Ann Emerg Med 2011;58(2):138-41.

2. Bukata R. Has triage become an intrusive waste of time? EM Abstracts; 12 June 2015. Available at: http://epmonthly.com/ article/has-triage-become-an-intrusive-waste-of-time/.

3. Horwitz LI, Green J, Bradley EH. US emergency department performance on wait time and length of visit. Ann Emerg Med 2010;55(2):133-41. doi:10.1016/j. annemergmed.2009.07.023.

4. Cheng AHY, Sutherland JM. British Columbia's pay-forperformance experiment: part of the solution to reduce emergency department crowding? Health Policy 2013;113:86-92.

5. Steiner D, Renetseder F, Kutz A, et al. Performance of the Manchester triage system in adult medical emergency patients: a prospective cohort study. 7 Emerg Med 2016; 50(4):678-89.
6. Gilboy N, Tanabe T, Travers D, et al. Agency for Healthcare Research and Quality. Emergency Severity Index (ESI): a triage tool for emergency department care, version 4. Implementation Handbook 2012 edition, publication no. 12-0014. Rockville: Agency for Healthcare Research and Quality; 2011.

7. Murray M, Bullard M, Grafstein E. Revisions to the Canadian emergency department triage and acuity scale implementation guidelines. Can 7 Emerg Med 2004;6(6): 421-7.

8. Innes K, Stackhouse S, Grafstein E, et al. Are CTAS time targets appropriate? What are emergency department patients' beliefs regarding appropriate physician response times? Can 7 Emerg Med 2012;14(Suppl 1):S27-9.

9. Schull M, Vermeulen M, Guttmann A, et al. Better performance on length-of-stay benchmarks associated with reduced risk following emergency department discharge: an observational cohort study. Can 7 Emerg Med 2015; 17(3):253-62, doi:10.1017/cem.2014.39.

10. Becker N, Friedman A. MD, heal thyself. Am 7 Emerg Med 2014;32(2):175-7.

11. Houston C, Sanchez L, Fischer C, et al. Waiting for triage: unmeasured time in patient flow. West 7 Emerg Med 2015; 16(1):39-42, doi:10.5811/westjem.2014.11.22824.

12. Levisman J, Price M. Update on the guidelines for the management of ST-elevation myocardial infarction. Am $\mathcal{J}$ Cardiol 2015;115(5):3A-9A.

13. Jauch E, Saver J, Adams H, et al. Guidelines for the early management of patients with acute ischemic stroke. Stroke 2013;44:870-947.

14. Yealy D, Huang D, Delaney A, et al. Recognizing and managing sepsis: what needs to be done? BMC Med 2015;13:98-108, doi:10.1186/s12916-015-0335-2.

15. Mandell L, Wunderink R, Anzueto A, et al. Thoracic Society consensus guidelines on the management of community-acquired pneumonia in adults. Clin Infect Dis 2007;44(Suppl 2):S27-72, doi:10.1086/511159. 